\title{
(2) OPEN ACCESS \\ Evaluating the impact of plain packaging among Canadian smokers: findings from the 2018 and 2020 ITC Smoking and Vaping Surveys
}

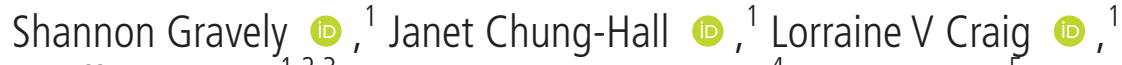 \\ Geoffrey T Fong, ${ }^{1,2,3} \mathrm{~K}$ Michael Cummings (1) , ${ }^{4}$ Ron Borland, ${ }^{5}$ Hua-Hie Yong (1) , ${ }^{6}$ \\ Ruth Loewen, ${ }^{1}$ Nadia Martin, ${ }^{1}$ Anne C K Quah, ${ }^{1}$ David Hammond, ${ }^{3}$ Janine Ouimet, ${ }^{1}$ \\ Christian Boudreau (1) , ${ }^{7}$ Mary E Thompson, ${ }^{7}$ Pete Driezen (1) ${ }^{1,3}$
}

\begin{abstract}
- Additional supplemental material is published online only. To view, please visit the journal online (http://dx.doi. org/10.1136/tobaccocontrol2021-056635).
\end{abstract}

'Department of Psychology, University of Waterloo, Waterloo, Ontario, Canada

${ }^{2}$ Ontario Institute for Cancer Research, Toronto, Ontario, Canada

${ }^{3}$ School of Public Health Sciences, University of Waterloo, Waterloo, Ontario, Canada ${ }^{4}$ Department of Psychiatry \& Behavioral Sciences, Medica University of South Carolina, Charleston, South Carolina, USA ${ }^{5}$ School of Psychological Sciences, University of Melbourne, Melbourne, Victoria, Australia

${ }^{6}$ Department of Psychology, Deakin University, Geelong, Victoria, Australia Department of Statistics and Actuarial Science, University of Waterloo, Waterloo, Ontario, Canada

\section{Correspondence to} Dr Shannon Gravely, Department of Psychology, University of Waterloo, Waterloo N2L 3G1, ON, Canada; shannon.gravely@uwaterloo.ca

Received 6 March 2021 Accepted 8 June 2021

Check for updates

(c) Author(s) (or their employer(s)) 2021. Re-use permitted under CC BY-NC. No commercial re-use. See rights and permissions. Published by BMJ.

To cite: Gravely S, ChungHall J, Craig LV, et al. Tob Control Epub ahead of print: [please include Day Month Year]. doi:10.1136/ tobaccocontrol-2021-056635

\section{ABSTRACT}

Background In February 2020, Canada implemented plain packaging without any changes to the size and content of health warning labels (HWLs), which were last updated in 2012 (pictorial HWLs on 75\% of the pack front and back). This pre-post evaluation study assessed the impact of plain packaging in Canada on: (1) pack appeal; (2) HWL effectiveness; and (3) support for plain packaging. Additionally, a quasi-experimental design was used to assess the Canadian results relative to two comparator countries: Australia, where plain packaging (with new larger HWLs) was implemented in 2012, and the United States (USA), where plain packaging has not been implemented and the same text warnings have appeared on cigarette packs since 1985.

Methods Data are from adult smokers who participated in the 2018 and/or 2020 International Tobacco Control Smoking and Vaping Surveys in Canada $(n=4600)$, Australia $(n=1834)$ and the USA $(n=3046)$. Online surveys were conducted before (February to July 2018) and after (February to June 2020) the implementation of plain packaging in Canada. Adjusted regression analyses were conducted on weighted data.

Results Plain packaging was associated with a significant increase in the percentage of Canadian smokers who did not like the look of their cigarette pack (2018: $28.6 \%$ vs 2020: $44.7 \%, p<0.001$ ), whereas no change in pack appeal was observed among smokers in Australia and the USA over the same period. Plain packaging was not associated with changes in HWL effectiveness in Canada. Support for plain packaging increased significantly among Canadian smokers (2018: $25.6 \%$ vs 2020: $33.7 \%, p<0.001$ ).

Conclusions Plain packaging in Canada substantially reduced pack appeal and increased support for the policy among adult smokers; however, there was no increase in the effectiveness of Canada's 8-year-old HWLs. The impact of plain packaging on health warning effectiveness may depend on the design of the warnings and length of time since implementation.

\section{INTRODUCTION}

Tobacco product packaging is an important marketing strategy for companies to differentiate their brands. ${ }^{12}$ The tobacco industry invests heavily in marketing the package to generate positive brand associations, which both promote and reinforce smoking. ${ }^{1-5}$ Because of these marketing strategies, the WHO calls on member states to strengthen their labelling policies and implement plain packaging. ${ }^{67}$ Also known as 'standardized packaging', plain packaging is the standardization of the appearance of packaging across brands and brand varieties via the removal of all brand imagery, including logos. All packages must use the same colour, with all text printed in standardized font and location. ${ }^{6}$

Plain packaging is recommended in Article 13 guidelines (tobacco advertising, promotion and sponsorship) ${ }^{8}$ of the WHO Framework Convention on Tobacco Control as a way to eliminate packagebased marketing. It is also recommended in Article 11 (packaging and labelling of tobacco products) ${ }^{9}$ because, in the absence of branding, warnings might become more noticeable and effective.

In December 2012, Australia became the first country in the world to introduce plain packaging, requiring all packs to be sold in logo-free, drab dark brown packaging of fixed dimensions. By 1 January 2021, fourteen additional countries had also implemented plain packaging. ${ }^{10}$

There are three major objectives of plain packaging: to reduce pack appeal, enhance the salience (eg, noticeability) and the effectiveness (eg, encourage smokers to quit) of health warning labels (HWLs) $^{6}$ and reduce misperceptions about the harmfulness of the product (eg, prohibit colours and descriptors that connotate reduced harm).

Experimental and qualitative studies have found that cigarettes in plain packaging are rated as less appealing (eg, are lower in quality, less attractive and taste worse) than cigarettes in branded packaging by youth and adults, smokers and non-smokers. ${ }^{11-16}$ Population-based studies that have evaluated the effect of plain packaging on appeal among smokers in Australia, ${ }^{5617-19}$ France, $^{20}$ England ${ }^{21} 22$ and New Zealand $^{23}$ have found that the introduction of plain packaging was associated with strong reductions in pack appeal.

HWLs increase the likelihood that smokers will think about the risks of smoking and the benefits of quitting, while reducing the ability of the packaging to convey false and misleading messaging about smoking harms. ${ }^{24}$ One of the primary aims of plain packaging is to remove competing elements on the package so that HWLs are more salient and impactful. Studies in England, ${ }^{21} 225$ New Zealand ${ }^{23}$ and Australia ${ }^{26}$ have found that the implementation 
of plain packaging concurrently with new larger pictorial HWLs increased warning salience, thoughts about the risks of smoking and motivation to quit smoking. A national tracking survey in Australia showed that plain packaging was associated with increased HWL noticeability and believability, as well as stronger cognitive and behavioural responses, such as greater motivation to quit smoking, avoidant responses (eg, pack concealment), stubbing out their cigarette early and stopping themselves from smoking when they had an urge. ${ }^{5} 1819$ A quasi-experimental study evaluated the effect of introducing new HWLs along with plain packaging in England compared with that of introducing new HWLs without plain packaging under the European Tobacco Products Directive (2014/40/EU, all implemented in 2016) ${ }^{2127}$ in Germany, Greece, Hungary, Poland, Romania and Spain. The study found that the new warnings were more salient in all countries, but this effect was greater in England. A study by Moodie $e t a l^{25}$ examined smokers' responses to HWLs (salience, other cognitive reactions, as well as behavioural reactions) before and after the implementation of plain packaging in the UK, where it was paired with larger and novel warnings, and in Norway, where there were no changes to the HWLs. They found that the warnings on plain packs were more effective in the UK, where warnings were enhanced, but not in Norway, where HWLs remained unchanged.

\section{Plain packaging in Canada}

In 2019, Canada introduced the Tobacco Products Regulations (Plain and Standardized Appearance) ${ }^{28}$ under the Tobacco and Vaping Products Act..$^{29}$ These regulations required that all tobacco products (manufactured cigarettes, roll-your-own products, cigars, cigarillos, pipe tobacco, heated tobacco products, smokeless tobacco products) be sold at the retail level in plain packaging starting on 7 February 2020. Nicotine vaping products (e-cigarettes) are exempt from plain packaging as they are not regulated as tobacco products. ${ }^{29}$

Unlike other countries that revised and enlarged HWLs concurrently with the implementation of plain packaging (eg, Australia, New Zealand, France and the UK), Canada's implementation of plain packaging was not accompanied by any change to the HWLs. Since 2012, warnings have covered $75 \%$ of the front and back of the pack. ${ }^{30}$ See online supplemental figure 1 for a full description of Canada's plain packaging regulations.

The implementation of plain packaging in Canada has provided further opportunity for assessing the impact of this regulation on the effectiveness of already existing HWLs, a departure from past evaluations of plain packaging in countries where it was accompanied by new, enhanced warnings, with the exception of Norway. ${ }^{25}$ This pre-post evaluation assessed the impact of plain packaging in Canada on: (1) pack appeal; (2) HWL effectiveness; and (3) support for plain packaging. Additionally, a quasiexperimental design compared the Canadian results to two countries where no changes in packaging occurred over the same time period: (1) Australia, where plain packaging was implemented in combination with new larger HWLs in 2012; and (2) the USA, where pack branding is permitted, and only minimal text warnings have appeared on the side of the cigarette packs since 1985 .

\section{METHODS}

\section{Sample and procedure}

Data are from wave 2 (22 February to 9 July 2018) and wave 3 (24 February to 1 June 2020; the Canadian survey closed on 31 May 2020) of the International Tobacco Control Four Country Smoking and Vaping (ITC 4CV) Survey, a longitudinal cohort survey of adult cigarette smokers and vapers from Canada, the USA, England and Australia. Respondents were recruited from web-based panels in each country using a stratified sampling design, and cohort respondents from the original ITC 4C Survey were also invited to participate. ${ }^{31} 32$ Respondents lost to attrition at each wave were replenished using the same sampling design. Further details about the ITC 4CV methods can be found elsewhere. ${ }^{33} 34$

Eligible respondents for the current study were those who completed either the 2018 or 2020 survey, or both surveys, who were established current smokers at the time of recruitment ( $\geq$ monthly and smoked at least 100 cigarettes in their lifetime). Respondents who were smokers at a given wave were included, but if those who were recontacted had quit smoking at wave 2 or wave 3 , they were excluded for that wave. Only data from Canada, Australia and the USA were included, as the results from smokers in England are published elsewhere. ${ }^{21}$

Table 1 describes the status of plain packaging and the mandated HWLs in each of the three countries in 2018 and 2020 .

\section{Measures}

\section{Outcome measures}

Three measures were used to examine smokers' responses to plain packaging regulations:

1. Pack appeal: Smokers who reported having a regular brand of cigarettes were asked: 'To what extent, if at all, do you like the look of your cigarette pack?' The responses were dichotomised into 'not at all' versus 'other' (a little/somewhat/quite a lot/very much/don't know).

2. Indicators of HWL effectiveness: box 1 describes each of the HWL indicator measures.

Salience of HWLs: This outcome was assessed using two measures: (1) what smokers noticed first on the pack (dichotomised as: 'warning labels first' vs 'something else'); and (2) how often smokers noticed the warning (dichotomised as: 'very often/often' vs 'other').

Cognitive reactions to HWLs: This outcome was assessed using two measures: (1) thinking about the health risks of smoking; and (2) thinking about quitting smoking. Responses were dichotomised into 'a lot' versus 'other'.

Behavioural responses to HWLs: This outcome was assessed using two measures: (1) forgoing a cigarette (dichotomised as: 'yes, at least once' vs 'no'); (2) avoiding the warnings (dichotomised as: 'yes' vs 'no').

3. Support for plain packaging: Support for plain packaging was asked in 2018 and 2020 in Canada and Australia, and in 2018 in the USA with the following question: 'Please tell us whether you agree or disagree ... Tobacco companies should be required to sell cigarettes in plain packages'. Responses were dichotomised into 'agree' versus 'otherwise' (disagree/neither agree or disagree/don't know).

\section{Covariates}

\section{Sociodemographic variables}

Sociodemographic data were collected by commercial panel firms and verified at the time of survey completion, including: age, gender, ethnicity, education and country of residence. Baseline measures (the point of their recruitment into the study) were used for all analyses.

\section{Smoking and vaping status}

Respondents reported the frequency that they smoke, and if they vaped or not at the time of survey completion (and if so, at what 


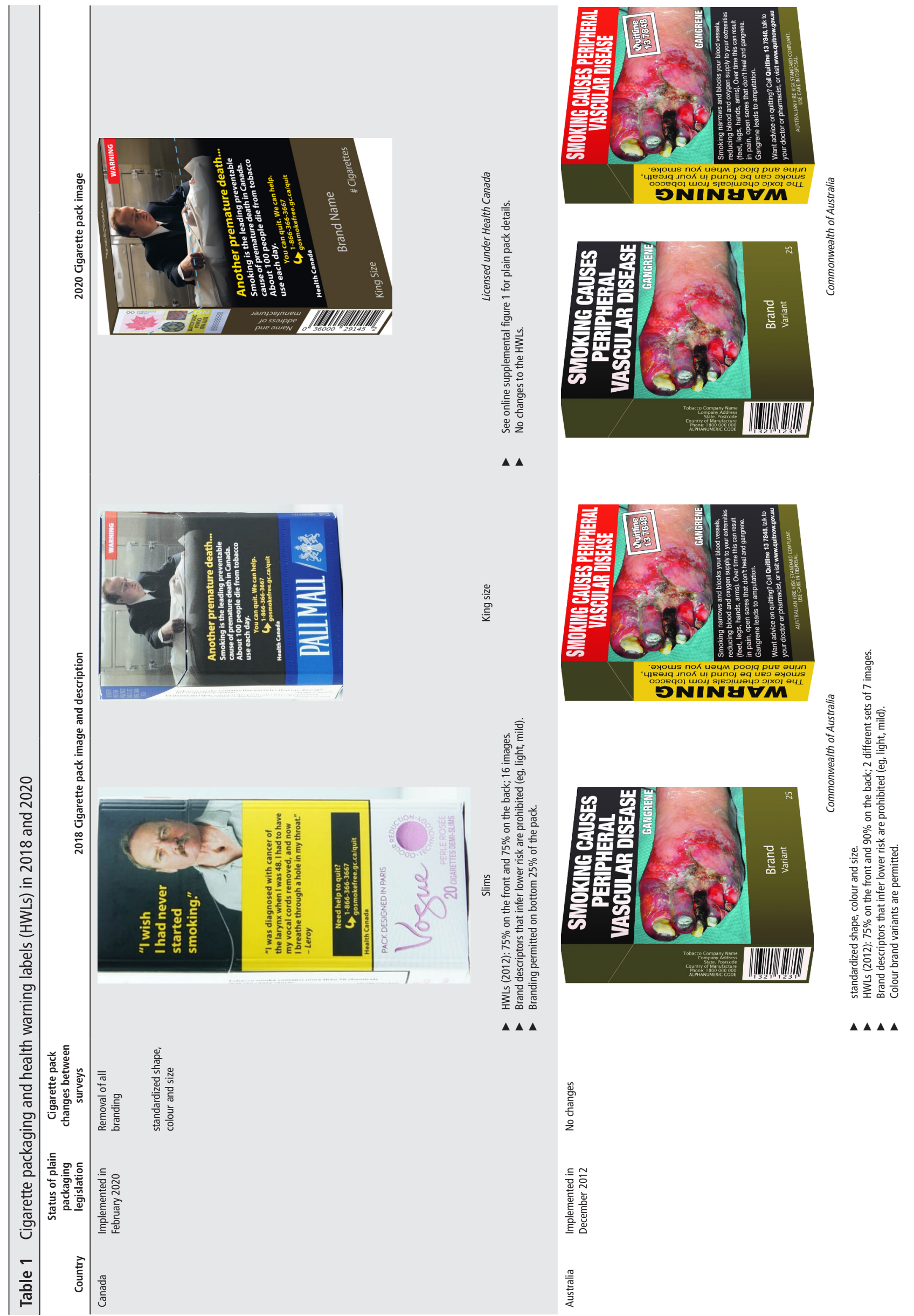




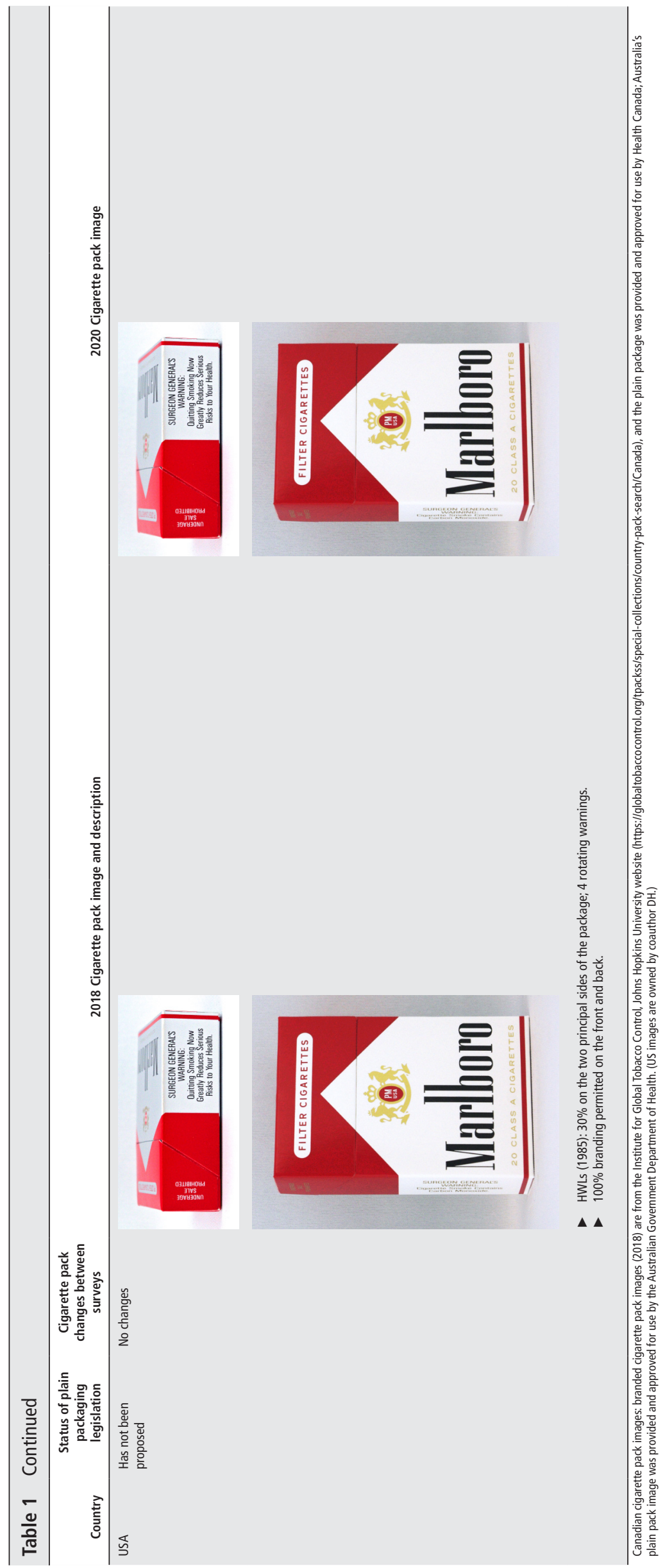


Box 1 International Tobacco Control (ITC) health warning label indicator survey questions

- When you look at a cigarette pack, what do you usually notice first-the warning labels, or other aspects of the pack such as branding? Response options: warning labels; other aspects of the pack such as branding; don't know. (Salience)

- In the last 30 days, how often, if at all, have you noticed the warning labels on cigarette packages? Response options: never, rarely, sometimes, often, very often, don't know. (Salience)

- To what extent, if at all, do the warning labels make you think about the health risks of smoking? Response options: not at all; a little; somewhat; a lot; don't know. (Cognitive)

- To what extent, if at all, do the warning labels make you more likely to quit smoking? Response options: not at all; a little; somewhat; a lot; don't know. (Cognitive)

- In the last 30 days, have you made any effort to avoid looking at or thinking about the warning labels_-such as covering them up, keeping them out of sight, using a cigarette case, avoiding certain warnings, or any other means? Response options: yes; no; don't know. (Behavioural)

- In the last 30 days, have the warning labels stopped you from having a cigarette when you were about to smoke one? Response options: never; once; a few times; many times; don't know. (Behavioural)

frequency). Smoking and vaping status at the time of survey completion (time varying) were used in the analyses.

\section{Wave of recruitment}

Respondents were included if they were from a previous cohort $(\leq 2015,2016,2018)$, or if they were newly replenished in 2018 or 2020 .

Table 2 provides definitions for the covariates included in the analyses.

\section{Data analysis}

Unweighted descriptive statistics were used to describe the study sample from each of the three countries. All other analyses were conducted on weighted data. After the weighting was applied, the sample in each country was designed to be nationally representative of cigarette smokers. ${ }^{31-34}$

Weighted multivariable logistic regression was used to estimate the percentage of smokers reporting changes for: (1) pack appeal (limited to those smokers having a regular brand); and (2) HWL effectiveness (all smokers). Logistic regression models were estimated using generalised estimating equations to account for within-subject correlation among smokers participating in both surveys. Analyses for all estimates are presented by country (within each country across time), as well as comparisons between countries (with Canada as the reference group). All models controlled for sex, age group, ethnicity, income, education, smoking status, vaping status and respondent type (cohort vs replenishment). Those who refused to answer were excluded.

Analyses were conducted using SAS-callable SUDAAN (V.11.0.3, RTI International) to account for the stratified sampling design and sampling weights. Adjusted percentages were estimated using average marginal effects in SUDAAN. ${ }^{35}$ Benjamini-Hochberg false discovery rate corrections controlled for multiple tests. ${ }^{36}$
Finally, a modified approach was used to examine changes in support for plain packaging because this question was not asked of US respondents in 2020. A five-level categorical measure was used: Canada 2018, 2020; USA 2018; Australia 2018, 2020. The same covariates listed above were used.

\section{RESULTS}

The (unweighted) sample characteristics of smokers participating in this study are presented in table 2.

\section{Effectiveness of plain packaging in Canada \\ Changes in pack appeal}

Figure 1 shows the changes in pack appeal.

Overall, there was a significant increase in the percentage of Canadian smokers who did not like the look of their pack from $28.6 \%$ in 2018 to $44.7 \%$ in 2020 ( $\mathrm{p}<0.001)$.

Country comparisons: There were no significant changes in pack appeal in Australia $(\mathrm{p}=0.45)$ or the USA $(\mathrm{p}=0.06)$. Although more Canadian smokers disliked the look of their pack in 2020 than in 2018, Australian smokers were more likely to dislike the look of their pack at both time points $(\mathrm{p}<0.001)$. Smokers in the USA were significantly less likely than Canadian smokers to report that they disliked the look of their pack in 2018 and $2020(\mathrm{p}<0.001)$.

\section{HWL effectiveness \\ HWL salience}

Figure 2 shows the changes in HWL salience.

Noticed HWLs first: There were no changes in Canadian smokers noticing HWLs first (compared with other pack elements) between pre-implementation and post implementation (2018: $35.2 \%$ vs 2020: $35.6 \%, \mathrm{p}=0.79$ ).

Country comparisons: Relative to Canadian smokers, Australian smokers had a higher rate of noticing HWLs first in 2018 $(\mathrm{p}=0.01)$, but there were no differences between the two countries in $2020(\mathrm{p}=0.22)$. Canadian smokers were significantly more likely than US smokers to notice HWLs first in 2018 and $2020(\mathrm{p}<0.001)$.

Noticed HWL 'very often/often' in the last 30 days: There were no differences among Canadian smokers often noticing HWLs between 2018 and 2020 (2018: 34.4\% vs 2020: 36.3\%, $\mathrm{p}=0.23)$.

Country comparisons: There was no difference among Australian smokers often noticing HWLs between 2018 and 2020 $(\mathrm{p}=0.46)$. There was no difference between Canada or Australia in $2018(\mathrm{p}=0.11)$ or in $2020(\mathrm{p}=0.13)$. There was a significant increase among US smokers often noticing HWLs between 2018 and $2020(\mathrm{p}<0.001)$. Relative to Canadian smokers, significantly fewer US smokers often noticed HWLs in $2018(\mathrm{p}<0.001)$ and $2020(\mathrm{p}=0.04)$.

\section{HWL cognitive responses}

Figure 3 shows the changes in cognitive responses to HWLs.

Thinking 'a lot' about the risks of smoking: There was no difference between 2018 and 2020 among Canadian smokers in thinking a lot about the risks of smoking (2018: $15.5 \%$ vs 2020 : $15.4 \%, \mathrm{p}=0.96)$.

Country comparisons: There were no changes over time among Australian or US smokers thinking a lot about the risks of smoking. Canadian smokers were significantly more likely to think a lot about smoking risks compared with Australian and US smokers in both 2018 and 2020 (all p<0.05). 
Table 2 Respondent characteristics (unweighted)

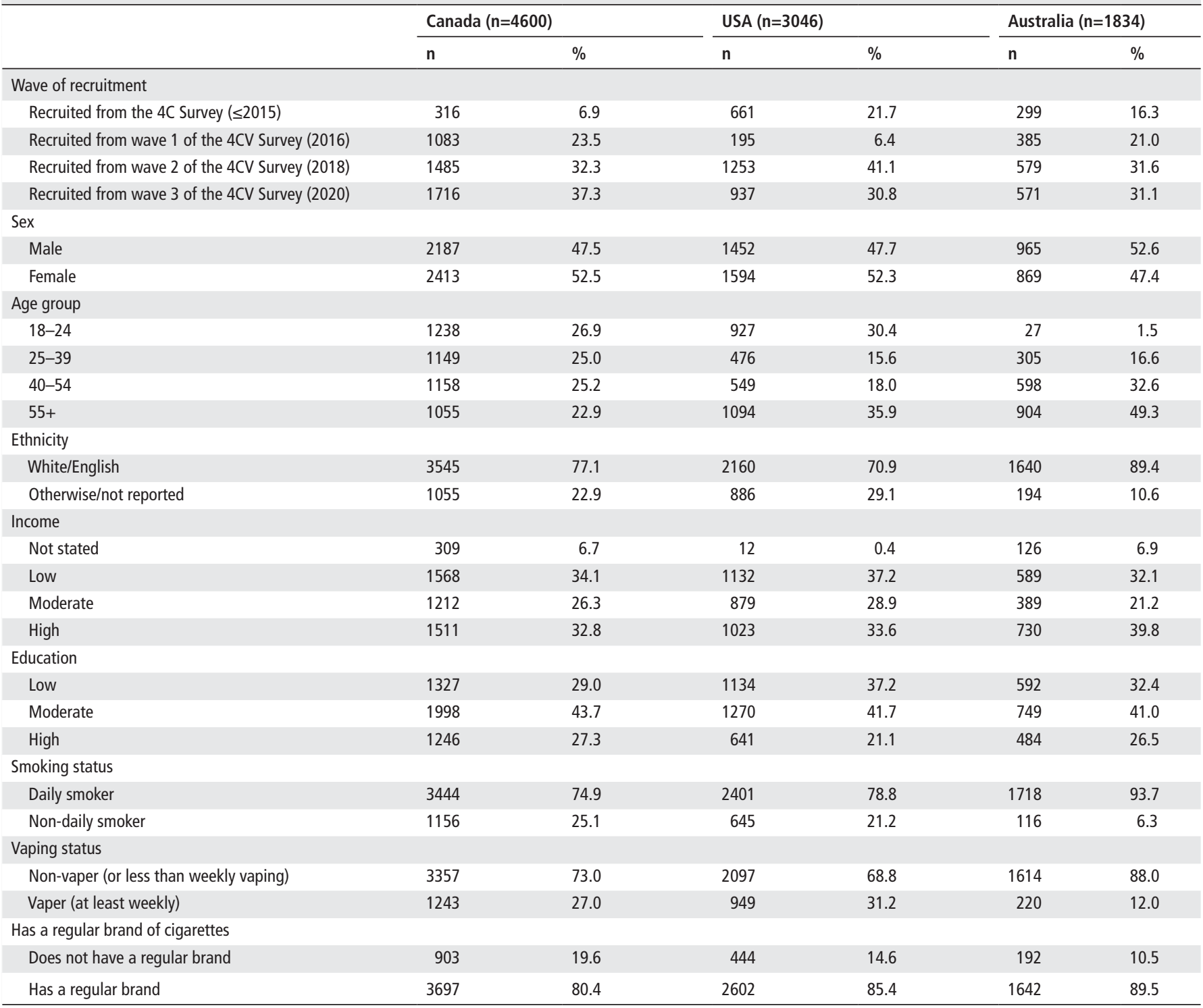

4C: previous ITC cohort surveys; 4CV: current ITC cohort surveys. Sex (male vs female); age group (18-24, 25-39, 40-54 vs 55+); ethnicity (White (CA, USA) or English as primary language (AU) vs otherwise); income (defined as low (CA, AU: $<\$ 45000$; USA: $<\$ 30000)$, moderate (CA, AU: $\$ 45000$ to $<\$ 75000 ;$ USA: $\$ 30000$ to $<\$ 60000)$, high (CA, AU: $\geq \$ 75000 ;$ USA: $\geq \$ 60000$ ), and not reported); education (defined as low (all countries: $\leq$ high school), moderate (CA: trade school, community college, some university but no degree; USA: trade school, community college, associate degree, or some university but no degree; AU: technical education or some university but no degree), and high (all countries: university degree or postgraduate degree)); respondent type (cohort: $\leq 2015,2016,2018$; new respondents: newly replenished in 2018 or 2020); smoking status (daily smoker vs non-daily smoker); and vaping status (does not vape/vapes less than weekly vs vapes at least weekly).

AU, Australia; 4C, Four Country Survey; CA, Canada; 4CV, Four Country Smoking and Vaping Survey; ITC, International Tobacco Control.

Thinking 'a lot' about quitting because of the HWLs: Fewer than $5 \%$ of Canadian smokers reported that the HWLs would make them 'a lot' more likely to quit smoking in 2018 and 2020 , and there were no changes between the pre-post measures $(\mathrm{p}=0.91)$.

Country comparisons: There was no significant change between 2018 and 2020 among smokers reporting that they would be a lot more likely to quit smoking because of the warning labels in Australia $(p=0.91)$ and the USA $(p=0.56)$. There were no differences between countries in 2018 (all p>0.05). In 2020, Canadian smokers were more likely than US smokers to report this $(p=0.04)$, but there was no difference between Canadian and Australian smokers $(\mathrm{p}=0.18)$.

\section{HWL behavioural responses}

Figure 4 shows the changes in behavioural responses to HWLs.
Gave up a cigarette 'at least once' because of the warnings: There was no pre-post change in the percentage of Canadian smokers reporting that they had given up a cigarette because of the HWLs (2018: $14.8 \%$ vs 2020: 13.2\%, $\mathrm{p}=0.18$ ).

Country comparisons: There was no difference among Australian smokers between 2018 and 2020 in giving up a cigarette because of the HWLs $(p=0.42)$. Canadian smokers were no more likely than Australian smokers to give up smoking a cigarette in $2018(\mathrm{p}=0.08)$, but they were more likely to do so in $2020(p=0.04)$. Among US smokers, there was a decrease in likelihood of forgoing a cigarette between 2018 and 2020 $(p=0.03)$. Canadian smokers were more likely than US smokers to forgo a cigarette because of the HWLs in both $2018(\mathrm{p}=0.03)$ and $2020(\mathrm{p}<0.001)$.

Avoiding warning labels: There was no pre-post change among Canadian smokers reporting that they avoided HWLs between 


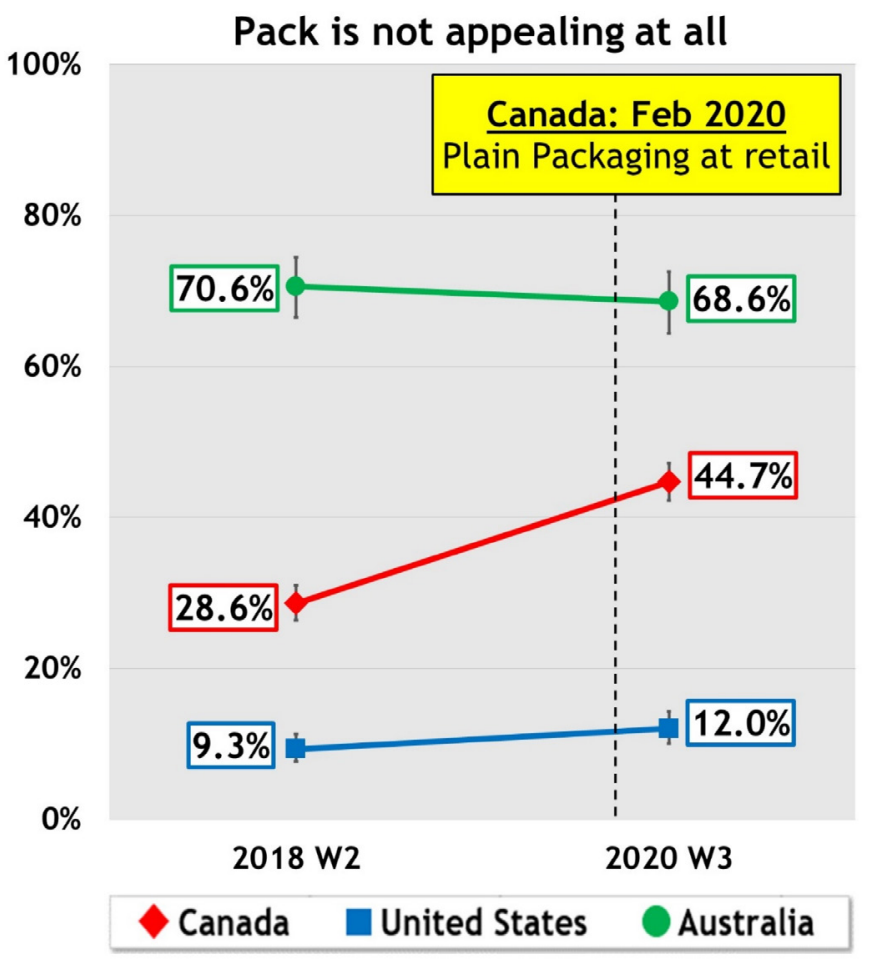

Figure 1 Percentage of smokers who reported that they 'do not like the look of their cigarette pack at all', by country and survey wave

2018 and $2020(p=0.48)$, where about $20 \%$ of smokers reported doing so at both time points.

Country comparisons: There were no differences among Australian or US smokers avoiding HWLs between 2018 and 2020. There were no differences between Canadian and Australian smokers at either time point (both p >0.05); however, Canadian smokers were significantly more likely than US smokers to report avoiding HWLs in 2018 and 2020 (both $\mathrm{p}<0.001$ ).

\section{Changes in support for plain packaging}

Figure 5 shows the changes in support for plain packaging.

There was a significant increase in support for plain packaging among Canadian smokers from $25.6 \%$ in 2018 to $33.7 \%$ in $2020(\mathrm{p}<0.001)$.

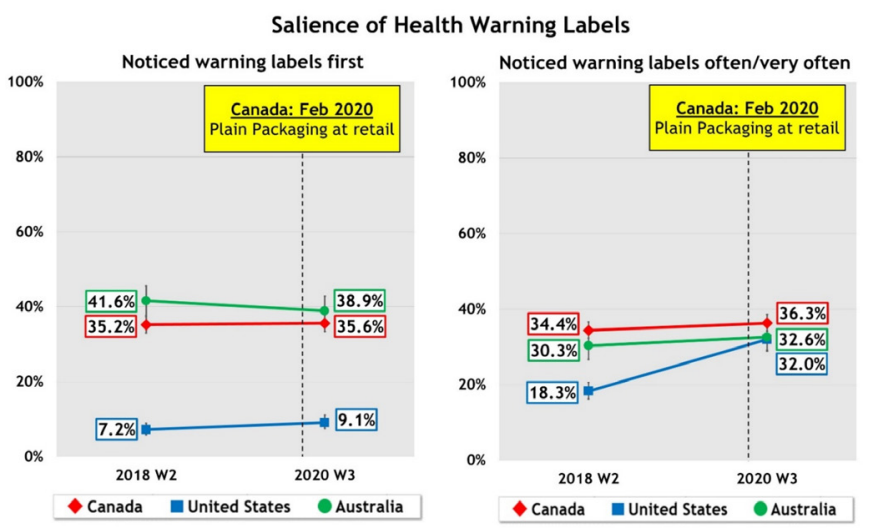

Figure 2 Percentage of smokers who said that they notice warning labels first when they look at a cigarette pack (vs other aspects of the pack such as branding), and noticed warning labels 'often' or 'very often', by country and survey wave

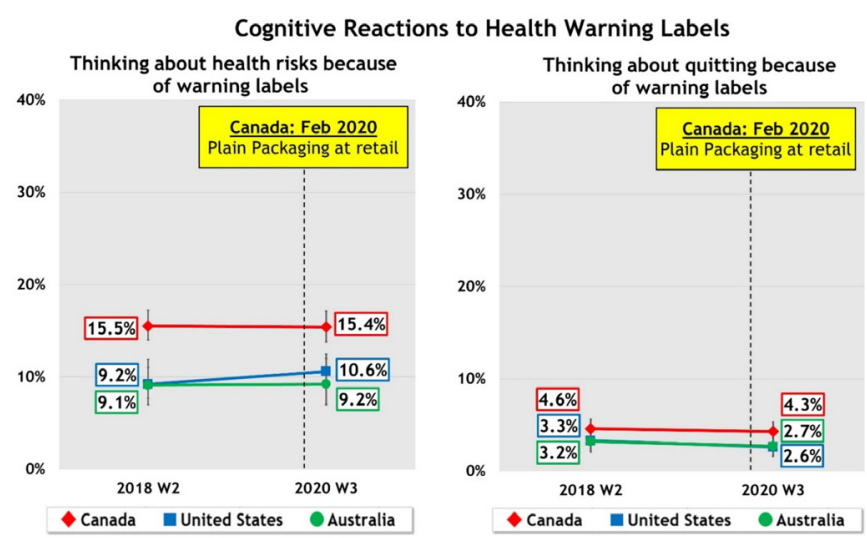

Figure 3 Percentage of smokers who thought 'a lot' about the health risks of smoking and about quitting smoking because of the warning labels.

Country comparisons: Support for plain packaging slightly increased in Australia between 2018 and 2020, but this was not significant $(\mathrm{p}>0.05)$. Canadian smokers were less likely than Australian smokers to support plain packaging in 2018 $(p=0.007)$, but there were no differences in $2020(p=0.73)$. Support for plain packaging was very low in the USA. Canadian smokers were more likely than US smokers to support plain packaging $(\mathrm{p}<0.001)$.

\section{DISCUSSION}

This pre-post study evaluated the impact of plain packaging on pack appeal and HWL effectiveness, as well as smokers' support for plain packaging in Canada. Overall, the findings showed that the implementation of plain packaging in Canada significantly reduced the appeal of cigarette packs, but did not increase the effectiveness of the 8-year-old HWLs. Smokers' support for plain packaging significantly increased after policy implementation. There were generally few differences between Canada and Australia, but US smokers had lower appeal ratings, were less likely to support plain packaging and reported lower levels of HWL effectiveness.

Plain packaging is an important measure to limit the differentiation and promotion of tobacco products, to denormalise tobacco use, particularly among youth and young adults, as well as to reduce pack appeal. ${ }^{6} 37-40$ The findings from this study are consistent with evaluations of plain packaging in other

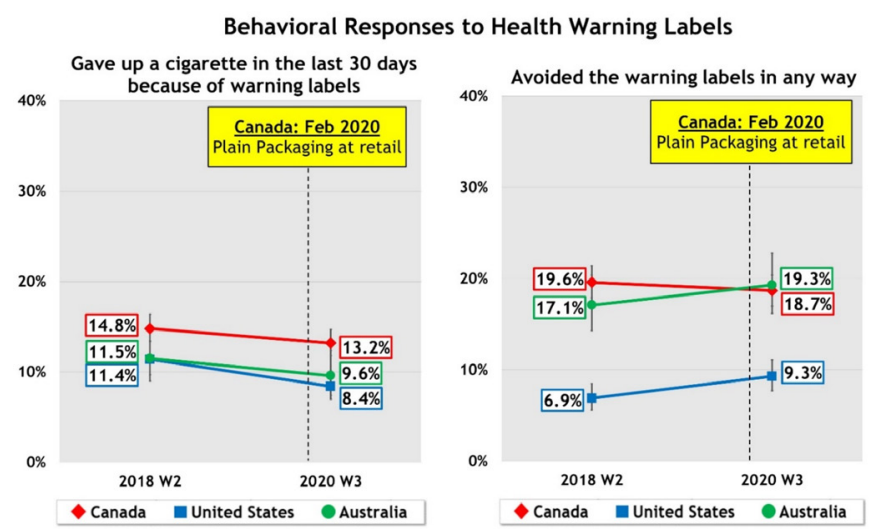

Figure 4 Percentage of smokers who said that they stopped themselves from smoking (at least once) and avoided looking at or thinking about the warning labels. 


\section{Support for plain packaging}

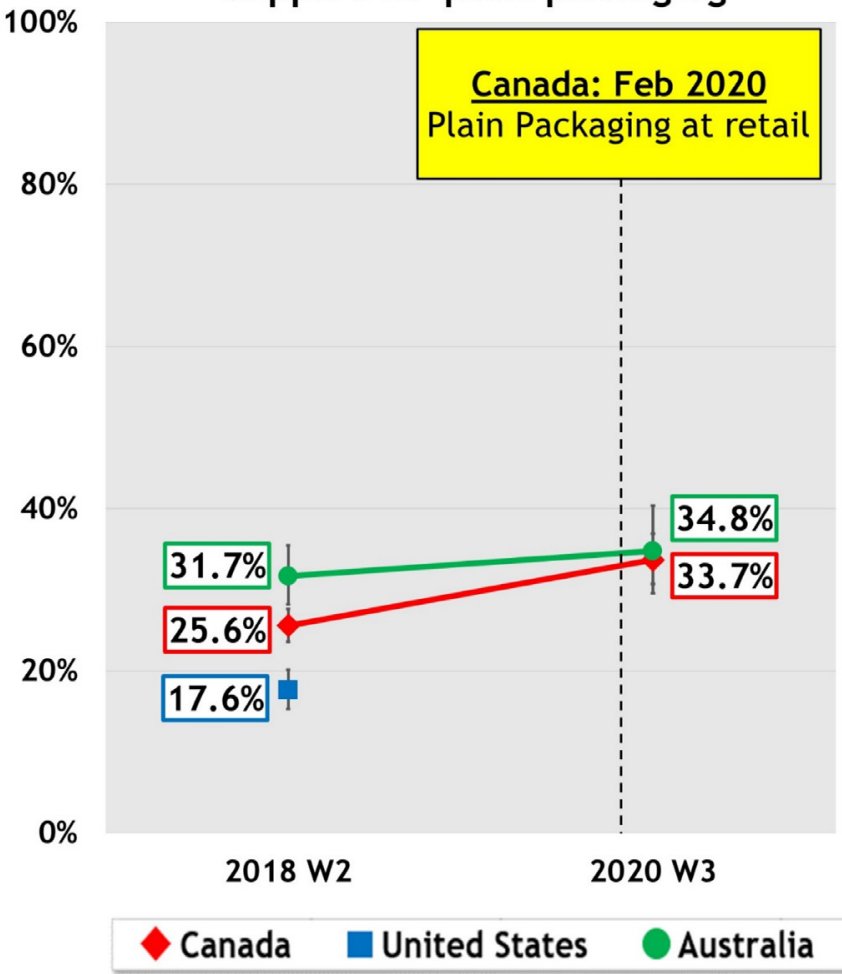

Figure 5 Percentage of smokers who 'agree' or 'strongly agree' that tobacco companies should be required to sell cigarettes in plain/ standardized packages, by country and survey wave.

countries, $51421-23$ showing that the regulation in Canada was associated with reduced pack appeal among current smokers. Specifically, there was a twofold increase in Canadian smokers who disliked the look of their pack after the implementation of plain packaging. However, data collected among smokers in England, ${ }^{22}$ New Zealand ${ }^{23}$ and Australia ${ }^{1819}$ showed that a much greater percentage of smokers disliked the look of their cigarette pack after plain packaging was implemented, compared with what we found in Canada. This difference may have been due to the new set of larger HWLs that were implemented concurrently with plain packaging in these other countries. That is, apart from the design of the rest of the pack, the larger HWLs and renewed content also influence these pack perceptions. Notably, the findings also indicate that branded packs are more appealing than plain packs, where in 2020,12\% of US smokers reported disliking the look of their pack compared with $45 \%$ of Canadian smokers and 69\% of Australian smokers.

Evaluation studies of the impact of plain packaging on HWL effectiveness in Australia, ${ }^{526}$ England $^{2122} 25$ and New Zealand ${ }^{23}$ found significant increases in salience and cognitive and behavioural reactions to the warnings. This study did not replicate these effects in Canada. There were, however, some marked differences in HWL effectiveness among US smokers relative to Canada (and sometimes Australia). For example, noticing warnings first on the pack was markedly higher in Canada and Australia relative to the USA. Additionally, Canadian smokers were more likely than US smokers to report that: they noticed HWLs in the last 30 days, HWLs made them think about the risks of smoking, the warnings would make them a lot more likely to quit smoking, they gave up a cigarette and avoided the warnings. The finding that US smokers reported a significant increase in noticing HWLs between 2018 and 2020 (from 18\% to 32\%), despite very weak warnings that have not changed since 1985 , was surprising-especially given that noticing warnings first on the pack (compared with other pack elements) was very low in the USA (less than 10\% at both time points). Post hoc analyses to assess whether the increase in past 30-day noticeability was related to sociodemographic factors, smoking or vaping frequency, and whether respondents participated in both waves or only one wave, did not explain these findings. Nevertheless, our findings showed that large graphic warnings in Canada (both before and after plain packaging) were substantially more effective than the US text warnings.

Our results were similar to a recent study that evaluated the impact of plain packaging in the UK and Norway. ${ }^{25}$ Prior to the implementation of plain packaging, both countries had the same size and type of warnings on cigarette packs (43\% text on the front, 53\% graphic on the back). After the implementation of plain packaging concurrently with novel larger warnings in the UK $(65 \%$ on the front and back, and the text warning on the front was replaced by a graphic warning), there was a significant increase in smokers noticing the warnings, thinking about the health risks of smoking, avoidant behaviours, forgoing cigarettes and being more likely to quit because of the warnings. In contrast, there was a significant decrease in noticeability, thinking about health risks of smoking, and being more likely to quit because of the warnings among smokers in Norway, where plain packaging was implemented without any changes to HWLs.

The finding of decreased effectiveness of warnings in Norway does differ from our Canadian findings, where there were no changes in effectiveness. This could reflect the smaller warnings in Norway with text-only warnings on the front of the pack; thus, there was a much larger portion of the pack that was subjected to standardization in Norway $(57 \%$ of the pack was changed) compared with Canada (where only $25 \%$ of the pack was changed). It could be that the pack changes in Norway may have caught the attention of smokers to a greater degree, thus taking attention away from the warnings. However, taken together, these findings provide the first real-world evidence that disentangles the impact of plain packaging on the salience and effectiveness of health warnings without the confounding effects of changes to the size and content of HWLs.

Studies from different countries-including Canada-have shown that the effectiveness of repeated health warnings and messages either plateaus or decreases over time on branded packs. ${ }^{41-43}$ The findings from our study, and Moodie et al, ${ }^{25}$ also support previous research on the effects of 'wear-out' when HWLs are not changed for some time, even when plain packaging is implemented. The Australian Government Department of Health also found a reduction in the impact of HWLs since they were introduced along with plain packaging in 2012, including less noticing of HWLs among smokers and recent quitters, and less avoidance of the warnings among smokers. ${ }^{44}$ The fact that plain packaging did not enhance the 8 -year-old Canadian warnings points to the power of wear-out in diminishing the impact of even large pictorial warnings, and thus the need for countries to revise and enhance their warnings much more frequently than current global practice. Plain packaging is an important and impactful measure, but it is not a panacea. The results from our study do suggest however that plain packaging may have delayed significant wear-out in Australia, as HWL effectiveness measures generally did not decrease between survey waves.

Public support for tobacco control measures encourages governments to implement and strengthen tobacco control laws. The post implementation increase in support for plain packaging among smokers in Canada was similar to increases in support observed in 
Australia, ${ }^{45}$ England ${ }^{22}$ and New Zealand, ${ }^{23}$ although the percentage of Canadian smokers who supported plain packaging post implementation was lower than in these other countries. A recent study by Moodie et al examined changes in support for plain packaging among current smokers in the UK across three waves of data (20162019) ${ }^{46}$ and found a significant pre-post increase in support for the measure (pre: $25.4 \%$ in 2016; post: $34.0 \%$ in 2017 and $35.4 \%$ in 2019). These estimates are consistent with our finding that Canadian smokers' support increased from $25.6 \%$ in 2018 to $33.7 \%$ in 2020. In contrast, we found very low support for plain packaging in the USA in 2018 (18\%), which is unsurprising in a country where the packs are still heavily branded, and pictorial HWLs have not yet been introduced.

This study has important strengths, including a quasiexperimental pre-post design (equivalent to a difference-in-difference design) of a large sample of representative smokers from three high-income countries. While previous population studies (with the exception of Moodie et $a l^{25}$ ) have examined the impact of plain packaging in combination with new and enlarged HWLs, the effects could not be disentangled from the impact of the enhanced HWLs. Thus, in addition to the examination of the impact of plain packaging in Norway (without changes to the warnings), ${ }^{25}$ the Canadian government's implementation of plain packaging without concurrent changes to HWLs also allows for this separation.

This study has some limitations to consider. First, because our sample comprised current adult smokers, we were not able to assess the impact of plain packaging on youth and non-smokers, where the appeal of packaging might be expected to be most impactful. Second, we did not assess the impact of plain packaging on those who were smoking before the plain packaging regulation took effect and had quit smoking by the time of our 2020 follow-up survey. Thus, we did not assess if recent ex-smokers directly attributed quitting to plain packaging. Third, only smokers who reported having a regular (usual) brand were asked the appeal question (do you like the look of your cigarette pack); therefore, this assessment did not take into account the possible differing appeal ratings for those who did not report having a regular brand (eg, non-brand loyal smokers).

\section{What this paper adds}

- Population-level evidence has shown that cigarette plain packaging, implemented concurrently with larger and refreshed pictorial health warning labels (HWLs), reduces the appeal of the pack, and increases the salience and effectiveness (eg, cognitive and behavioural reactions) of the warnings.

- In February 2020, Canada implemented plain packaging, but unlike other countries (eg, Australia, New Zealand, France and the UK), Canada did not change (eg, enlarge or refresh) the existing HWLs at the same time that plain packaging was introduced. This study thus allowed for evaluation of the impact of plain packaging independent of enhancements to HWLS.

- Plain packaging accompanied by existing HWLs in Canada led to reduced pack appeal and stronger support for the policy. However, there was no increase in the effectiveness of the 8-year-old HWLs.

- These findings suggest that impact of plain packaging on health warning salience may depend on their design and the number of years since implementation.

\section{CONCLUSION}

The implementation of plain packaging in Canada provided an opportunity for assessing the impact of this measure on the noticeability and effectiveness of already existing HWLs, a departure from past evaluations of plain packaging in countries where it was accompanied by new, enhanced warnings, with the exception of one study. ${ }^{25}$ The introduction of plain packaging in Canada led to reduced pack appeal and stronger support for the policy, but there was no increase in the effectiveness of the 8 -year-old HWLs. These findings suggest that impact of plain packaging on health warning salience may depend on their design and the number of years since implementation. Notably, when all evaluation studies are considered, the collective findings suggest that plain packaging may act synergistically with changes in HWL size and content to reduce pack appeal and to enhance the salience of warnings. In other words, plain packaging is likely to have the strongest impact on all measures of effectiveness when it is implemented in combination with larger HWLs that feature refreshed content.

\section{Twitter Geoffrey T Fong @gfong570}

Acknowledgements The authors would like to acknowledge and thank all those who contributed to the International Tobacco Control Four Country Smoking and Vaping (ITC 4CV) Survey: all study investigators and collaborators, and the project staff at their respective institutions. We acknowledge the comments from Cynthia Callard, Physicians for a Smoke-Free Canada; Rob Cunningham, Canadian Cancer Society; and Francis Thompson, HealthBridge, on drafts of this paper.

Collaborators Cynthia Callard, Physicians for a Smoke-Free Canada; Rob Cunningham, Canadian Cancer Society; Francis Thompson, HealthBridge.

Funding This study (ITC 4CV) was supported by grants from the US National Cancer Institute (P01 CA200512), the Canadian Institutes of Health Research (FDN-148477), and the National Health and Medical Research Council of Australia (APP 1106451). GTF was supported in part by a Senior Investigator Award from the Ontario Institute for Cancer Research and by the 0 . Harold Warwick Prize from the Canadian Cancer Society. Funding for this manuscript was provided by Health Canada's Substance Use and Addictions Program (SUAP) Arrangement \#2021-HQ000058. The views expressed herein do not necessarily represent the views of Health Canada.

Competing interests KMC has served as a paid expert witness in litigation filed against cigarette manufacturers. GTF and DH have served as expert witnesses on behalf of governments in litigation involving the tobacco industry, including challenges to plain packaging regulations. GTF and SG served as paid expert consultants to the Ministry of Health of Singapore in reviewing the evidence on plain/standardized packaging.

\section{Patient consent for publication Not required.}

Ethics approval Study questionnaires and materials were reviewed and provided clearance by the Research Ethics Committees at the following institutions: University of Waterloo (Canada, ORE\#20803/30570, ORE\#21609/30878), Cancer Council Victoria, Australia (HREC1603), Deakin University, Australia (HREC2018-346), University of Queensland, Australia (2016000330/HREC1603); and the Medical University of South Carolina (waived due to minimal risk). All participants provided consent to participate.

Provenance and peer review Not commissioned; externally peer reviewed.

Data availability statement Data are available upon reasonable request. All data relevant to the study are included in the article or uploaded as supplementary information. The data are jointly owned by a third party in each country that collaborates with the International Tobacco Control Policy Evaluation (ITC) Project. Data from the ITC Project are available to approved researchers 2 years after the date of issuance of cleaned data sets by the ITC Data Management Centre. Researchers interested in using ITC data are required to apply for approval by submitting an International Tobacco Control Data Repository (ITCDR) request application and subsequently to sign an ITCDR Data Usage Agreement. To avoid any real, potential or perceived conflict of interest between researchers using ITC data and tobacco-related entities, no ITCDR data will be provided directly or indirectly to any researcher, institution or consultant that is in current receipt of any grant monies or in-kind contribution from any tobacco manufacturer, distributor or other tobaccorelated entity. The criteria for data usage approval and the contents of the Data Usage Agreement are described online (http://www.itcproject.org). The authors of this paper obtained the data following this procedure. This is to confirm that others 
would be able to access these data in the same manner as the authors. The authors did not have any special access privileges that others would not have.

Open access This is an open access article distributed in accordance with the Creative Commons Attribution Non Commercial (CC BY-NC 4.0) license, which permits others to distribute, remix, adapt, build upon this work non-commercially, and license their derivative works on different terms, provided the original work is properly cited, appropriate credit is given, any changes made indicated, and the use is non-commercial. See: http://creativecommons.org/licenses/by-nc/4.0/.

\section{ORCID iDs}

Shannon Gravely http://orcid.org/0000-0001-5224-9105

Janet Chung-Hall http://orcid.org/0000-0002-9139-8100

Lorraine V Craig http://orcid.org/0000-0001-5269-1817

K Michael Cummings http://orcid.org/0000-0002-7103-7017

Hua-Hie Yong http://orcid.org/0000-0001-8167-6173

Christian Boudreau http://orcid.org/0000-0003-3106-1319

Pete Driezen http://orcid.org/0000-0003-2320-0999

\section{REFERENCES}

1 National Cancer Institute. The role of the media in promoting and reducing tobacco use. tobacco control monograph No. 19. Bethesda, MD: U.S. Department of Health and Human Services, National Institutes of Health, National Cancer Institute, 2008: 07-6242.

2 Campaign for Tobacco-Free Kids. Tobacco pack branding - theory and practice. Supporting evidence. Available: https://www.tobaccofreekids.org/plainpackaging/tools-resources/policy/ tobacco-pack-branding-theory-and-practice [Accessed 5 Mar 2020].

3 Al-Hamdani M. Plain packaging policy: preventing industry innovations. Can J Public Health 2017;108:e98-100.

4 Wakefield M, Morley C, Horan JK, et al. The cigarette pack as image: new evidence from tobacco industry documents. Tob Control 2002;11(Suppl 1):i73-80.

5 Australian Department of Health. Post-Implementation Review (PIR) - Tobacco Plain Packaging, 2016. Available: https://ris.pmc.gov.au/sites/default/files/posts/2016/02/ Tobacco-Plain-Packaging-PIR.pdf [Accessed 5 Mar 2020].

6 World Health Organization. Plain packaging of tobacco products: evidence, design and implementation. Geneva: Switzerland:WHO Press, 2016.

7 World Health Organization. World no tobacco day 2016: get ready for plain packaging., 2016. Available: https://www.who.int/campaigns/no-tobacco-day/2016/ en/ [Accessed 5 Mar 2020].

8 World Health Organization. WHO report on the global tobacco epidemic, 2013: enforcing bans on tobacco advertising, promotion and sponsorship. Geneva: Switzerland:WHO Press, 2013.

9 World Health Organization. WHO report on the global tobacco epidemic, 2011: warning about the dangers of tobacco. Geneva: Switzerland: WHO Press, 2011.

10 Canadian Cancer Society. Plain packaging - international overview, 2020. Available: https://www.cancer.ca/ /media/cancer.ca/CW/get\%20involved/take\%20action/ Tobacco\%20control/plain-packaging-overview-2019-07-05.pdf?la=en [Accessed 5 Mar 2020].

11 Chantler S. Standardised packaging of tobacco. Report of the independent review undertaken by Sir Cyril Chantler, 2014. Available: https://www.kcl.ac.uk/health/ 10035-TSO-2901853-Chantler-Review-ACCESSIBLE.PDF [Accessed 5 Mar 2020].

12 Hammond D. Standardized packaging of tobacco products: evidence review. Prepared on behalf of the Irish Department of Health, 2014.

13 Hughes N, Arora M, Grills N. Perceptions and impact of plain packaging of tobacco products in low and middle income countries, middle to upper income countries and low-income settings in high-income countries: a systematic review of the literature. BMJ Open 2016;6:e010391.

14 McNeill A, Gravely S, Hitchman SC, et al. Tobacco packaging design for reducing tobacco use. Cochrane Database Syst Rev 2017;4:CD011244.

15 Moodie C, Stead M, Bauld L. A. plain tobacco packaging: a systematic review. U.K. Centre for Tobacco Control Studies, University of Stirling., 2012.

16 Moodie C, Angus K, Stead M. Plain tobacco packaging research: an update. Stirling, Scotland: Centre for Tobacco Control Research, Institute for Social Marketing, University of Stirling, 2013.

17 Balmford J, Borland R, Yong H-H. Impact of the introduction of standardised packaging on smokers' brand awareness and identification in Australia. Drug Alcohol Rev 2016;35:102-9.

18 Wakefield M, Coomber K, Zacher M, et al. Australian adult smokers' responses to plain packaging with larger graphic health warnings 1 year after implementation: results from a national cross-sectional tracking survey. Tob Control 2015;24:ii17-25.

19 Dunlop SM, Dobbins T, Young JM, et al. Impact of Australia's introduction of tobacco plain packs on adult smokers' pack-related perceptions and responses: results from a continuous tracking survey. BMJ Open 2014;4:e005836.

20 Pasquereau A, Andler R, Guignard R, et al. Smokers' perception of cigarette packaging in France before and after the plain packaging. Eur J Public Health 2020;30.

21 Aleyan S, Driezen P, McNeill A, et al. Evaluating the impact of introducing standardized packaging with larger health-warning labels in England: findings from adult smokers within the EUREST-PLUS ITC Europe surveys. Eur $J$ Public Health 2020;30:iii91-7.

22 British Heart Foundation and the ITC Project. Standardised packaging for tobacco products in England: evidence of policy impact from the International tobacco control policy evaluation project, 2020. Available: https://itcproject.org/findings/reports/standardisedpackaging-tobacco-products-england-evidence-policy-impact-international-tobacco-controlpolicy-evaluation-project-feb-2020 [Accessed 5 Mar 2020].

23 ITC Project. Standardised packaging for tobacco products in New Zealand: evidence of policy impact from the International tobacco control policy evaluation project, 2020. Available: https://www.otago.ac.nz/wellington/departments/publichealth/ research/otago735056.pdf [Accessed 5 Mar 2020].

24 Hammond D. Health warning messages on tobacco products: a review. Tob Control 2011:20:327-37

25 Moodie C, Best C, Lund I, et al. The response of smokers to health warnings on packs in the United Kingdom and Norway following the introduction of standardised packaging. Nicotine Tob Res 2021;18:ntab027.

26 Yong H-H, Borland R, Hammond D, et al. Smokers' reactions to the new larger health warning labels on plain cigarette packs in Australia: findings from the ITC Australia project. Tob Control 2016;25:181-7.

27 Canadian Cancer Society,. Cigarette package health warnings: international status report. 4th edn, 2014. https://www.cancer.ca/ /media/cancer.ca/CW/For\%20media/ Media\%20releases/2014/Tobacco\%20Warnings\%200ct\%202014/CCS-internationalpackage-warnings-report-2014-ENG.pdf

28 Government of Canada. Tobacco products regulations (plain and standardized appearance) (SOR/2019-107), 2019. Available: https://laws-lois.justice.gc.ca/eng/ regulations/ SOR-2019-107/index.html [Accessed 5 Mar 2021].

29 Government of Canada. Vaping product regulations. Available: https://www.canada. ca/en/health-canada/services/smoking-tobacco/vaping/product-safety-regulation.html [Accessed 5 Mar 2021].

30 Canadian Cancer Society. Cigarette package health warnings. Available: https://www. cancer.ca/en/get-involved/take-action/what-we-are-doing/tobacco-control/cigarettepackaging/?region=on [Accessed 5 Mar 2021].

31 Thompson ME, Fong GT, Boudreau C, et al. Methods of the ITC four country smoking and Vaping survey, wave 1 (2016). Addiction 2019;114(Suppl 1):6-14.

32 ITC Project. ITC four country smoking and Vaping survey wave 1 (2016) technical report. University of Waterloo, Waterloo, Ontario, Canada; Medical University of South Carolina, Charleston, South Carolina, United States; Cancer Council Victoria, Melbourne, Australia; King's College London, London, United Kingdom, 2018.

33 ITC Project. ITC four country smoking and Vaping survey, wave 2 (2018) technical report. University of Waterloo, Waterloo, Ontario, Canada; Medical University of South Carolina, Charleston, South Carolina, United States; Cancer Council Victoria, Melbourne, Australia; the University of Queensland, Australia; King's College London, London, United Kingdom, 2020.

34 ITC Project. ITC four country smoking and Vaping survey, wave 3 (4CV3, 2020) preliminary technical report. University of Waterloo, Waterloo, Ontario, Canada; Medical University of South Carolina, Charleston, South Carolina, United States; Cancer Council Victoria, Melbourne, Australia; the University of Queensland, Australia; King's College London, London, United Kingdom, 2020.

35 Muller CJ, MacLehose RF. Estimating predicted probabilities from logistic regression: different methods correspond to different target populations. Int J Epidemiol 2014;43:962-70

36 Benjamini Y, Hochberg Y. Controlling the false discovery rate: a practical and powerful approach to multiple testing. Journal of the Royal Statistical Society 1995:57:289-300.

37 Cohen JE, Zhou S, Goodchild M, et al. Plain packaging of tobacco products: lessons for the next round of implementing countries. Tob Induc Dis 2020;18:93.

38 Ahmad MH, Ibrahim MI, Ab Rahman A, et al. Tobacco Denormalization indicator in the prevalence of positive smoker identity and its associated factors. Int I Environ Res Public Health 2020;17:2363.

39 Calabro KS, Costello TC, Prokhorov AV. Denormalization of tobacco use and the role of the pediatric health-care provider. Pediatr Allergy Immunol Pulmonol 2010;23:273-8.

40 WHO. WHO report on the global tobacco epidemic 2019. Geneva, Switzerland: WHO Press, 2019.

41 Hitchman SC, Driezen P, Logel C, et al. Changes in effectiveness of cigarette health warnings over time in Canada and the United States, 2002-2011. Nicotine Tob Res 2014; 16:536-43.

42 Swayampakala K, Thrasher JF, Yong H-H, et al. Over-time impacts of pictorial health warning labels and their differences across smoker subgroups: results from adult smokers in Canada and Australia. Nicotine Tob Res 2018;20:888-96.

43 Green AC, Kaai SC, Fong GT, et al. Investigating the effectiveness of pictorial health warnings in Mauritius: findings from the ITC Mauritius survey. Nicotine Tob Res 2014;16:1240-7.

44 Essence Communications. Evaluation of effectiveness of graphic health warnings on tobacco product packaging. An evaluation report. prepared for the Department of Health 2018

45 Swift E, Borland R, Cummings KM, et al. Australian smokers' support for plain or standardised packs before and after implementation: findings from the ITC four country survey. Tob Control 2015;24:616-21. 
